\title{
IDENTIDADE, LÍNGUA E CULTURA NAPOLITANAS NAS OBRAS DE LUCIANO DE CRESCENZO
}

\section{Maria Celeste Tommasello Ramos* Matheus dos Santos Bueno**}

Resumo: Analisamos como o escritor italiano Luciano De Crescenzo insere o dialeto napolitano em suas obras ficcionais, tais como em Così parlò Bellavista (1977), Elena, Elena, amore mio (1991), Nessuno (1997) e Ulisse era un fico (2010a). Embasamo-nos, acerca dos estudos sobre identidade e dialeto, respectivamente, nos autores Raimondi (1998) e Santos e De Blasi (2010) para investigar como o uso dialetal demarca a identidade e a cultura napolitanas. Verificamos que, apesar de as obras serem escritas em italiano standard, ao inserir frases, ditos populares, expressões idiomáticas e canções na variante dialetal no discurso dos personagens e nos comentários do narrador, o autor explora a realidade linguística daquela região italiana.

Palavras-chave: Luciano De Crescenzo. Dialeto napolitano. Identidade.

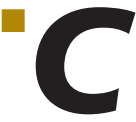

omo cidadão napolitano que enaltece sua cidade natal, o escritor Luciano De Crescenzo dirige a ela diversas considerações, principalmente em sua obra-prima Così parlò Bellavista, best-seller que o fez mudar da carreira de engenheiro da IBM para escritor da Editora Mondadori e que foi transmutado para o cinema com título homônimo, com participação dele na elaboração do roteiro e na atuação como um dos personagens da trama. Nessa obra, expõe uma visão filosófica inusitada e divertida sobre a constituição da identidade do napolitano em contraposição ao milanês e faz uso de expressões em dialeto napolitano como marca de identidade ligada a diversos aspectos relativos à história de formação da Itália.

\footnotetext{
Universidade Estadual Paulista "Júlio de Mesquita Filho" (Unesp), São José do Rio Preto, SP, Brasil. E-mail: celeste_ibilce@hotmail. com

** Universidade Estadual Paulista "Júlio de Mesquita Filho" (Unesp), São José do Rio Preto, SP, Brasil. E-mail: matheus.s.bueno@ hotmail.com.
} 
Em Così parlò Bellavista, desde o início do prefácio, o escritor já aponta o gênero ambíguo do texto e declara estar apresentando aos leitores uma obra escrita entre saggistica e narrativa (DE CRESCENZO, 1977, p. 7), ou seja, entre os gêneros de ensaio ou crônica e o narrativo de ficção, com a finalidade de levar o leitor a "capire Napoli” (entender Nápoles) (DE CRESCENZO, 1977, p. 8). Na mesma página, conta que, tempos antes, foi necessário que fizesse diversas observações sobre sua cidade natal e a população local a um amigo milanês que iria passar alguns dias em Nápoles, por ocasião do feriado da Páscoa. Viu então que suas explicações tinham sido muito proficuas, pois induziram seu amigo e seus familiares a entender com benevolência todos os acontecimentos vivenciados naqueles dias e os tinham predisposto a uma maior compreensão a respeito da realidade napolitana. Refletindo a respeito de tais observações, percebeu que seriam úteis para explicar o modo de vida dos napolitanos para mais pessoas e se dispôs, então, a escrever a obra que resultou, de maneira inusitada, em uma descrição do povo, da cultura local, por meio, inclusive, do uso do dialeto, visto que Nápoles, para ele, "não é a cidade de Nápoles, mas somente um componente do ânimo humano, que sei que se pode encontrar em todas as pessoas, sejam napolitanas ou não"1 (DE CRESCENZO, 1977, p. 8, tradução nossa).

O objetivo inicial que o levou a escrever sua obra-prima o movimentou a realizar uma escritura em uma metodologia inovadora, como ele mesmo declara:

A vontade de escrever esta minha "coisa" diretamente em dialeto e ao mesmo tempo o desejo de ser entendido, sobretudo pelos meus amigos não napolitanos, levaram-me a usar um método particular de trabalho: falei em dialeto todos os textos diante de um gravador e, posteriormente, traduzi pacientemente, palavra por palavra, os vocábulos napolitanos aos próprios correspondentes em língua italiana standard de modo que todos os diálogos pudessem conservar sua sintaxe dialetal (DE CRESCENZO, 1977, p. 10, tradução nossa) ${ }^{2}$.

Houve, como podemos ver nessa declaração, a intenção explícita do escritor em conservar a sintaxe dialetal, de forma que o aspecto da lingua do povo foi bastante valorizado por ele no momento de descrever os costumes locais àqueles que lhes eram alheios. Na sequência do prefácio, o escritor continua raciocinando a respeito do uso do dialeto e afirma o seguinte:

Mas desejar que o dialeto possa desaparecer para que esta espécie de exorcismo consiga favorecer uma melhor inserção dos napolitanos na realidade politica do país equivale, a meu ver, a matar por excesso de amor. Raciocinando nesse sentido, não vejo motivo para não passar diretamente à língua inglesa, visto que o único contexto político e econômico hoje ainda válido não é mais aquele italiano, mas o europeu (DE CRESCENZO, 1977, p. 10, tradução nossa) ${ }^{3}$.

\footnotetext{
"non è la città di Napoli ma solo una componente dell'animo umano che so di poter trovare in tutte le persone, siano esse napoletane o no."

2 "La voglia di scrivere questa mia 'cosa' direttamente in dialetto e nel contempo il desiderio di essere capito sopratutto dai miei amici non napoletani, mi ha portato quindi ad usare un particolare metodo di lavoro: ho recitato in dialetto tutti $i$ testi davanti ad un registratore e successivamente ho tradotto pazientemente, parola per parola, $i$ vocaboli napoletani nei propri corrispettivi in lingua in modo che tutti i dialoghi conservassero una loro sintassi dialettale."

3 "Ma desiderare che il dialetto possa sparire perché questa specie di esorcismo riesca a favorire un migliore inserimento dei napoletani nella realtà politica del paese, equivale a mio avviso ad uccidere per troppo amore. Ragionando in tal senso allora non vedo perché non passare direttamente alla lingua inglese, dal momento che l'unico contesto politico ed economico oggi ancora valido non è più quello italiano ma quello europeo."
} 
De forma que as considerações sobre Nápoles estão, na visão do escritor Luciano De Crescenzo, estritamente ligadas ao uso da linguagem popular constituída pelo dialeto napolitano e traduzida para os leitores "não napolitanos" por ele, na obra Così parlò Bellavista e em outras obras suas também.

Assim, pensando na afirmação de Raimondi (1998, p. IX, tradução nossa) ${ }^{4}$ de que "A identidade de um povo se forma de uma memória comum, que deve ser crítica para poder guardar lucidamente o passado" e que a instituição que a mantém, por meio da palavra, é a literatura, entendemos a possibilidade de ver, nas considerações literárias e filosóficas do texto decrescenziano, o modo de buscar a compreensão da italianidade por meio do delineamento da identidade do napolitano, refletindo, assim, a respeito das diversas maneiras sobre o "ser" italiano a partir do confronto entre a forma de ver a vida dos napolitanos e a dos milaneses.

A nosso ver, é isso que faz Luciano De Crescenzo principalmente em Così parlò Bellavista, mas também em outras obras literárias de sua autoria, como nas três em que reescreve narrativas mitológicas intertextualmente: Elena, Elena amore mio (publicada pela primeira vez em 1991), Nessuno (publicada pela primeira vez em 1997) e em Ulisse era un fico (publicada pela primeira vez em 2001), pois utiliza nelas a referência ao dialeto napolitano para transmitir conteúdos diversos.

Em Così parlò Bellavista, por exemplo, em diversos capítulos, faz uso de expressões em dialeto e insere notas de rodapé para explicá-las em italiano standard: "Não acredite nele engenheiro, aquele Saverio é ainda apaixonado pela

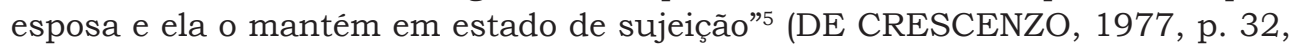
tradução nossa). Na nota de rodapé correspondente ao número inserido logo após a última palavra citada, podemos ler: "Lo tiene in stato di soggezione", ou seja, "tenerlo sotto al pacchero", que significa, no contexto, "mantê-lo em estado de sujeição". O dialeto é usado no momento em que a fala de um personagem napolitano ocorre.

Já em Elena, Elena, amore mio, recriação intertextual tendo como texto-fonte homérico Ilíada, no prefácio o escritor usa a expressão "Fare filone" (DE CRESCENZO, 1991, p. 10), que, na nota de rodapé trazida logo após essa frase, é explicada com a expressão em italiano standard "marinare la scuola", ou seja, "enforcar ou cabular aula", no português.

Em outras páginas, palavras específicas do dialeto são explicadas nas notas, como na página 91, em cuja nota de rodapé a palavra dialetal "pornal" é explicada assim: "Le pornai, da non confondere con le etere, erano le prostitue di strada, quelle d'infimo ordine", que em português: "As pornai, não confunda com as etere, eram as prostitutas de rua, aquelas da mais baixa classe". Ou na página 242, em cuja nota se pode ler:

Esta cena me faz lembrar de uma velha poesia de Salvatore Di Giacomo. O poeta está se dirigindo contra a mulher que acabou de traí-lo, quer insultá-la, quer fazer-lhe alguma coisa ruim, mas quando a vê mais linda que nunca, termina por dizer: "Pobre coração meu, pobre coração, como rapidamente se convence!

\footnotetext{
4 "L'identità di un popolo si forma da una memoria comune, che deve essere critica per poter guardare lucidamente al passado."

5 "Non lo date retta ingegnè, che quello Saverio è ancora innamorato della moglie e lei lo tiene sotto al pacchero."
} 
Mesmo que devesse provocar mais dor, eu quero fazer as pazes, sim, quero fazer as pazes!" (DE CRESCENZO, 1991, p. 242, tradução nossa) ${ }^{6}$.

O trecho de uma poesia em dialeto é convocado para a prosa literária, como numa lembrança do narrador que o cita, e, em nota de rodapé, a tradução para o italiano standard é acrescentada.

Já em Nessuno, podemos encontrar um outro trecho que trata diretamente das lembranças do narrador empírico Luciano De Crescenzo (1997, p. 17, tradução nossa) que declara:

Recordam-me uma canção napolitana antiga de Salvatore Di Giacomo, intitulada exatamente "À sereia". Fala de um velho pescador ao qual havia sido recomendado não passar próximo à ilha de Prócida. Minha mãe a cantava sempre:

Si passe scanzate, ca c'è pericolo:

ce sta na' femmena che 'nganna l'uommene

s' 'e chiamma e all'ultemo e fa murì.

[...]

Nota 1 Tradução para os não napolitanos:

Se você passa ali afaste-se, há um perigo:

existe uma mulher que engana os homens.

Primeiro os chama para si e depois os faz morrer ${ }^{7}$.

É exatamente da mesma cançãozinha que cantarolava sua mãe que De Crescenzo (2010a, p. 156) irá lembrar-se novamente, na parte dedicada ao herói Ulisses, quando fala novamente das sereias, em Ulisse era un fico:

A me ricordano una vecchia canzone napolitana di Salvatore Di Giacomo intitolata per l'appunto "A Sirena". Parla di un vecchio pescatore al quale era stato tanto raccomandato di non passare mai vicino Procida. La canticchiava sempre mia madre.

Si passe, scánzate,

ca c'è pericolo!

Ce sta'na femmena

ca 'ncanta ll'ummene...

se cchiamma e, a ll'úrdemo,

po"' e ffa murí!

[...]

Nota 1 Traduzione per i non napoletani:

"Se passi, scansati

che c'è pericolo!

C'è una donna

che inganna gli uomini...

6 Questa scena mi ricorda una vecchia poesia di Salvatore Di Giacomo. Il poeta è adirato contro la donna che lo ha appena tradito, vorrebbe insultarla, vorrebbe farle chissà che cosa, ma quando la vede più bella che mai, chiude dicendo: 'Povero core mio, povero core, / comm'ampresso te faie bell'e capace / dopo c'avesse avé n'ato dulore, / voglio fa pace, sì, voglio fa pace!' (Povero cuore mio, povero cuore, come presto ti convinci! Anche se dovessi avere un altro dolore, voglio far pace, si, voglio far pace!)."

7 "A me ricordano una vecchia canzone napoletana di Salvatore Di Giacomo intitolata per l'appunto 'A sirena'. Parla di un vecchio pescatore al quale era stato tanto raccomandato di non passare mai vicino Procida. La canticchiava sempre mia madre:/ Si passe scanzate, ca c'è pericolo:/ ce sta na' femmena che 'nganna l'uommene/ s' 'e chiamma e all'ultemo e fa murì./ [...]/ Nota 1 Traduzione per i non napoletani:/ Se passi scansati che c'è un pericolo:/ c'è una donna che inganna gli uomini./ Prima li chiama a sé e poi li fa morire." 


\section{prima li chiama}

e poi li fa morire.

Trata-se exatamente da mesma citação, somente os versos da canção aparecem agora divididos de forma diferente, com algumas consoantes duplas diferentes, com o verbo "'ncanta" em lugar de "'nganna" (encantar em lugar de enganar), mas o conteúdo é o mesmo, e o parágrafo que os introduz tem somente uma palavra a mais: "tanto". Ou seja, é a mesma recordação do escritor que é transmitida pela boca do narrador empírico, tão comum nas obras decrescenzianas. $\mathrm{O}$ fato de a grafia ser levemente diferente pode estar ligado ao fato de que o dialeto é muito mais falado por ele do que escrito, de forma que, ao escrevê-lo por duas vezes distintas, em obras diferentes, ele acaba por grafar de forma diferente.

O napolitano Luciano De Crescenzo, ao recontar a narrativa mitológica de Ulisses, no trecho em que trata das sereias, lembra-se duas vezes da mesma cançãozinha napolitana que sua mãe cantarolava sempre e a reproduz no dialeto, para dar bem as cores de sua identidade napolitana, mesmo quando não está diretamente enfocando os aspectos de Nápoles, como fez em Così parlò Bellavista.

De Crescenzo nasceu na primeira metade do século XX, na década de 1930, quando na península itálica os dialetos de cada cidade eram muito fortes, sobrepondo-se, na maior parte das vezes, à língua italiana standard (baseada no dialeto florentino e cunhada na segunda metade do século anterior, após a unificação da Itália, em 1861).

Costamagna (1995, p. 260-261) afirma que, por ocasião da união dos estados italianos, isto é, quando a Itália de fato se tornou um só país, somente $2,5 \%$ da população falava o italiano standard. Essa lingua era como que "estrangeira" para a maior parte da população que, para comunicar-se oralmente, usava os dialetos regionais. Até mesmo os governantes e os literatos falavam mal o italiano. O conde Camillo Benso di Cavour, político italiano que ocupou o cargo de primeiro-ministro, a partir de 1861, por exemplo, falava o dialeto piemontês e a lingua francesa e mandava traduzir seus discursos do francês para o italiano para pronunciá-los em público. Alessandro Manzoni, escritor, poeta e senador italiano, famosíssimo à época da união, escrevia em italiano, porém falava o dialeto milanês.

Para alguns escritores como Ítalo Svevo (1861-1928), por exemplo, o uso do dialeto em âmbito familiar acarretava, de certa forma, um problema de desconhecimento da língua nacional. Esse problema acompanhou-o por toda a vida, apesar de ter obtido certa segurança com o passar dos anos. É importante notar que a cidade de Trieste, sua cidade natal, naquela época, possuía um substrato cultural mais austríaco que italiano, visto que o território era ainda submisso à Áustria.

Não foi esse o caso de Luciano De Crescenzo. O uso do dialeto napolitano não o impedia de usar com propriedade o italiano standard, e, como pudemos verificar nos trechos selecionados, ele passava com facilidade do uso de um para outro, a ponto de conceber oralmente toda a obra Così parlò Bellavista no dialeto, como uma espécie de lingua materna que lhe facilitava a criatividade (tendo em vista que seu foco era a vida napolitana), e traduzir, ao escrever a obra literária, concretizando-a em italiano standard, mas sem deixar completamente de fora o dialeto, mostrando-o em alguns momentos em que tocavam o conhecimento regional, os usos napolitanos, ou a memória familiar, de alguma forma. 


\section{O ESPAÇO NAPOLITANo}

Como vimos, ao esclarecer a inspiração e o desejo de escrever Così parlò Bellavista, De Crescenzo reflete sobre o uso do dialeto napolitano na composição da obra e declara que primeiro concebeu a obra em dialeto, gravando-a em áudio para que, além de conservar a sintaxe do dialeto, pudesse inserir, em quase todos os capítulos da narrativa principal e das narrativas secundárias, frases, ditos populares ou palavras em dialeto napolitano.

No capítulo 10, intitulado "Mia Madre", caracterizado pelo gênero da crônica e da autobiografia, De Crescenzo (2010b, p. 79, tradução nossa) explicita a proximidade que teve com o dialeto no âmbito familiar, definindo-o como parte da herança cultural de sua família: "Minha mãe nasceu em 1883, quando a união da Itália não tinha ainda completado vinte anos. Na minha casa, os meus pais e sobretudo meus avós falavam exclusivamente em napolitano"8. O uso exclusivo do napolitano revela a conexão da família do autor com esse dialeto e, principalmente, as diferentes experiências linguísticas que ele e os avós tiveram, isto é, seus avós nasceram anteriormente a união da Itália (1861), quando o italiano ainda não era obrigatório, sendo, então, o dialeto o principal idioma com o qual eles se comunicavam, enquanto o contexto do neto Luciano era do uso do napolitano em ocasiões informais, em família ou entre amigos, e do italiano em ocasiões formais como escola e trabalho.

No que se refere à língua italiana, podemos afirmar que a Itália tem uma rica diversidade linguística, fruto da evolução do latim vulgar e da influência das diversas outras linguas e dialetos introduzidos por povos vizinhos: os franceses, os espanhóis, os gregos e outros que vieram para esse país ou passaram por ele, séculos antes de ser unificado. A cultura desses povos influenciou a arquitetura, a arte e também a língua daqueles que já habitavam a região. $\mathrm{O}$ napolitano é um dos muitos dialetos dentre os diversos que existem no país. Segundo Raffaele Bracale (2010), estudioso do dialeto napolitano:

Hoje se pode tranquilamente afirmar que o dialeto/idioma napolitano, unanimemente reconhecido, é um idioma romântico que, além do italiano, é correntemente falado (não apenas na Itália meridional, mas também no estrangeiro entre os milhões de imigrantes que queiram ainda se sentir próximos à terra de origem) nas suas múltiplas variações diatópicas; é falado nas regiões da Campania, Basilicata, Calabria setentrional, Abruzzo, Molise, Puglia e no Lazio meridional, na fronteira com a Campania, com as devidas variedades pela proveniência ou pela localização geográfica dos falantes ${ }^{9}$.

De forma que se pode ver como possui abrangência.

Ainda segundo Bracale (2010), é dificil precisar quando nasceu o dialeto napolitano, mas é possivel datar o surgimento do seu uso por volta do ano de 1442 . Ainda segundo o estudioso, considerando as características fonológicas, morfo-

8 "Mia madre nacque nem 1883, quando I'unità d'Italia non aveva ancora compiuto vent'anni. Nella mia casa i miei genitori e sopratutto i miei nonni parlavano exclusivamente in napoletano."

9 "Oggi si può tranquillamente affermare che il dialettolidioma napoletano, così come unanimemente riconosciuto, è un idioma romanzo che, accanto all'italiano, è correntemente parlato (non solo in Italia meridionale, ma anche all'estero tra le migliaia di emigrati che vogliono ancora sentirsi vicini alla terra d'origine) nelle sue molteplici variazioni diatopiche; è parlato cioè nelle regioni della Campania, Basilicata, Calabria settentrionale, Abruzzo,Molise, Puglia e nel Lazio meridionale, al confine con la Campania, con le variabilità dovute alla provenienza o alla collocazione geografica dei parlanti." 
lógicas e sintáticas, esse dialeto tem como base o latim vulgar falado e traços do substrato da língua osca ${ }^{10}$.

O contato linguístico com os povos gregos, bizantinos, franceses, normandos e árabes, segundo Bracale (2010), apenas representa um acréscimo do tipo lexical, não influenciando nos aspectos fonéticos, morfológicos e sintáticos do dialeto. Ainda que haja influências da lingua desses povos, as que mais sobressaíram, por acrescentaram léxico ao dialeto napolitano, foram as da lingua espanhola, em específico o castelhano, pelo longo contato desse povo no território italiano, entre, aproximadamente, 1503 e 1707.

Em virtude da força da cultura napolitana que foi se estabelecendo durante séculos, é possivel rastrear diversas manifestações de arte, principalmente de canções, poemas e outras formas de literatura registradas em dialeto. Entre os vários escritos descobertos, em um napolitano ainda em formação, isto é, ainda com fortes características do latim vulgar, encontra-se um da metade do século XIV, considerado como um dos primeiros textos escritos em dialeto, intitulado Cronaca di Partenope. Segundo Samantha Kelly (2011, p. 3), os estudiosos dessa obra acreditam que ela foi escrita por diversos autores, mas um patrício de Nápoles, chamado Bartolomeo Caracciolo-Carafa, é tido como o seu principal autor. Segundo a autora, a obra pode ser considerada a primeira história de Nápoles escrita, ainda que não seja útil em relação aos eventos históricos. Kelly (2011, p. 9, tradução nossa) afirma:

A Cronaca di Partenope é de muito pouca utilidade para a reconstrução dos eventos da história napolitana. A maior parte de sua narrativa diz respeito ao passado distante e é fortemente bordada por lendas, nas quais são registrados eventos verificáveis que dependem de fontes textuais que geralmente são superiores a ela em confiabilidade. Mas como um exemplo da articulação da identidade comum por meio da lembrança do passado é uma fonte rica e viva. Pode nos dizer o que a napolitaneidade significava em meados do século XIV não apenas para esse autor, mas também para os autores das fontes recentes em que ele se baseou e para o patriciado leigo que ele representava. Pode nos dizer como o passado foi organizado para responder ao presente e, em seu entrelaçamento de autoridades textuais, objetos fisicos e conhecimento comum local, sobre o oficio de se lembrar de si mesmo ${ }^{11}$.

As primeiras partes da obra referem-se às monarquias que governaram a região em diferentes periodos. A parte mais instigante dela é a quarta, na qual são relatadas antigas tradições sacras e profanas, além da referência a contos, lendas e histórias, mesclando a memória da tradição do povo relatadas ao serem citados monumentos gregos e latinos, hoje desaparecidos, e nomes de antigas regiões da cidade.

10 “1. Hist. Referente aos oscos, antigo povo dos montes Apeninos, Itália, que se estabeleceram entre a Campânia e o território dos volscos e fundaram a cidade de Pompeia 2. Ling. Língua indo-europeia do ramo itálico, falada pelos oscos". Trecho retirado do Dicionário Aulete digital. Disponível em: http://www.aulete.com.br/osco. Acesso em: 26 fev. 2019.

11 "The Cronaca di Partenope is of very little use for reconstructing the events of Neapolitan history. The bulk of its narrative concerns the distant past and is heavily embroidered with legend; where it records verifiable events, it relies on textual sources that are generally superior to it in reliability. But as an instance of the articulation of communal identity through recollection of the past, it is a rich and lively source. It can tell us what Neapolitanness meant in the mid-fourteenth century, not only to this one author but to the authors of the recent sources he relied upon and to the lay patriciate he represented. It can tell us how the past was marshalled to respond to the present, and in its interweaving of textual authorities, physical objects, and local common knowledge, about the craft of remembering itself." 
A Cronaca di Partenope interessa-nos sobremaneira, pois remonta ao dialeto napolitano e especialmente à descrição dos costumes de Nápoles, ainda chamada de Partenope, indicando o apreço desse povo em registrar, literariamente, seu espaço e seus costumes.

No momento em que a Itália passava pelo período fascista (1922-1943), durante o governo de Mussolini, discutiu-se qual o dialeto mais propício a ser usado como lingua oficial. Nesse sentido, cabe a reflexão sobre o que diferencia uma língua oficial de um dialeto. Segundo Franco Zappettini (2016), o dialeto da região onde se desenvolvem a política e a economia mais fortes se torna o idioma nacional. O dialeto, portanto, é o idioma da região cujas características externas à língua não se desenvolveram tanto quanto o da região que se tornou centro da política e da economia. Zappettini (2016, p. 14, tradução nossa) afirma:

Também a relatividade da distinção entre língua e dialeto deve fazer referência a condições sociais específicas, histórias, politicas, econômicas, que fazem sim que uma forma dialetal se torne standard como lingua e percebida como mais prestigiada que outros dialetos. Nesse sentido é muito importante notar como a língua não é uma entidade fixa, e como ela constitui a forma estandardizada não é um fato natural e objetivo, mas uma construção social. A distinção entre língua e dialeto, então, nasce do produto ideológico do Estado-nação mais do que de critérios puramente linguísticos ${ }^{12}$.

Assim, podemos entender que o dialeto é o idioma da região que não desenvolveu condições externas à língua, como a cultura, economia ou influência política. Na Itália, a região que detinha essas características mais desenvolvidas era a Toscana. Portanto, foi escolhida como lingua oficial da Itália o dialeto toscano, por conta do prestígio, influência dessa região e também pela vasta produção literária consolidadas por grandes escritores, como Petrarca, Boccacio e Dante Alighieri.

As escolas teriam que ensinar apenas o italiano standard, baseado no dialeto toscano, e as rádios e outros meios de comunicação deveriam apenas se comunicar por meio dessa lingua. Consequentemente, os outros dialetos foram suprimidos e usados apenas por aqueles que não tinham acesso à escola. Então, os diferentes dialetos regionais em todas as regiões da Itália foram passados de geração em geração e sobreviveram somente nos contextos familiar e cultural. Como visto anteriormente, De Crescenzo teve contato com o dialeto napolitano por intermédio dos pais e avós.

Diante da obrigação do uso do italiano proveniente da Toscana e do conturbado período fascista por que a Itália passava, muitos italianos valiam-se de seus próprios dialetos como forma de sedimentar sua cultura, sua região e seu contexto em obras artísticas elaboradas nessa linguagem familiar. Levando em conta que qualquer tipo de regionalismo, principalmente do uso do dialeto, era considerado uma provocação ao governo, muitos romances, contos e canções foram escritos em dialeto, representando seus autores e de onde eles vieram ao mesmo tempo que representavam uma forma de resistência artística à ditadura

12 "Inoltre la relatività della distinzione tra língua e dialetto deve fare riferimento a specifiche condizioni sociali, storiche, politiche, economiche che fanno sì che una forma dialettale venga standardizzata come lingua e percepita come più prestigiosa degli altri dialetti. In questo senso è quindi importante notare come la lingua non sia un'entità fissa e come ciò che costituisce la forma standard di una lingua non sia un fato naturale ed oggettivo ma una costruzione sociale. La distinzione tra lingua e dialetto quindi può spesso essere il prodotto ideologico dello stato-nazione piuttosto che scaturire da criteri puramente linguistici." 
política. Além dos muitos romances regionais escritos nesse período, o cinema também floresceu nesse aspecto e lançou diversos nomes, com destaque para o cineasta e escritor Pier Paolo Pasolini, com ênfase para o romance Ragazzi di vita, publicado em 1955, e, no cinema, os filmes Accatone, lançado em 1961, e Il Decameron, lançado em 1971.

Ainda assim, conforme o tempo passava, o uso massivo do italiano standard nas rádios e na televisão e o ensino nas escolas reduziram os dialetos ao contexto familiar, sendo usados cada vez menos. Contudo, especialistas afirmam que os jovens, atualmente, têm se interessado em usar o dialeto por ser, justamente, o elemento que os liga aos seus avós e à sua cultura. Segundo Carlo Cauti (2017), para a revista Exame:

[...] hoje o dado surpreendente é o aumento da porcentagem das pessoas que usam alternadamente o italiano e um dialeto: em 1955 eram 18\% da população, hoje mais de 44,1\%. Segundo muitos especialistas, esse renovado interesse pelos dialetos se tornou uma questão de identidade territorial, já que os mais atraídos pelos dialetos são os jovens, fascinados pela antiga língua de seus avós.

A questão da identidade cultural e o aumento do uso do dialeto pelos jovens, como pontuado por Cauti (2017), destacam a relação entre povo e lingua. Ademais, a cultura musical e a literária também são responsáveis por manter o dialeto napolitano vivo. Canções como "O' surdato nnamorato" ou "Funiculi funicula", entre outras, são conhecidas e cantadas na Itália e em vários outros países. Além disso, o renovado interesse pelo dialeto napolitano tem se intensificado devido aos novos programas de televisão, como a série sobre a máfia napolitana intitulada Gomorra, baseada na máfia real Comorra, gravada toda em dialeto napolitano e distribuída com legenda em italiano standard para o resto do país.

Ademais, a situação do uso entre o italiano e o napolitano, já que uma situação de bilinguismo foi criada por conta da obrigatoriedade do uso da língua oficial e do uso do dialeto nos contextos íntimos de fala, levou, segundo Nicola De Blasi (2006 apud MARANO, 2010, p. 155), à criatividade na comunicação pelos falantes, como podemos claramente verificar nas obras decrescenzianas por nós estudadas, visto que De Crescenzo escreveu tanto sua obra-prima como as reescrituras mitológicas em italiano, mas inseriu frases e palavras do dialeto nos diálogos e nas descrições. Esse uso dos dois idiomas concomitantemente pelo autor não está longe da realidade linguística dos napolitanos.

Frequentemente, segundo De Blasi (2006, p. 283 apud MARANO, 2010, p. 155), a população da cidade e região usa o dialeto e a língua oficial nos mesmos contextos linguísticos, principalmente quando uma das línguas não expressa exatamente o que se quer dizer, quando se recorre à outra. Segundo esse estudioso, o dialeto é procurado como função expressiva e lúdica: "o longo hábito do bilinguismo provavelmente favoreceu uma certa inclinação para o expressionismo linguístico espontâneo, a discussão, o jogo de palavras nascido no ponto de colisão entre napolitano e italiano"13 (DE BLASI, 2006, p. 283 apud MARANO, 2010, p. 155, tradução nossa).

13 "la lunga abitudine al bilinguismo ha probabilmente favorito una certa inclinazione all'espressionismo linguistico spontaneo, al bisticcio, al gioco di parole nato sul punto di collisione fra napoletano e italiano." 
Levando em consideração a rica história do dialeto napolitano, a importância dele na composição dos personagens e, consequentemente, na caracterização do espaço configurado literariamente por De Crescenzo, recolhemos exemplos do seu uso também em Così parlò Bellavista.

Apresentamos assim dez trechos selecionados dos diálogos nos quais aparecem sentenças inteiras em dialeto napolitano e dez palavras usadas em outros diálogos de personagens variados. Depois dessas palavras, exibiremos outro quadro com o uso do dialeto apenas pelo personagem Salvatore, com o intuito de analisar como o napolitano aparece mais nos discursos diretos desse personagem. Apresentaremos também, quando houver, a tradução, ou explicação, para o italiano feita pelo próprio De Crescenzo em notas de rodapé e uma proposta de tradução nossa para o português de cada uma delas, tendo como base o dialeto napolitano, mas sem desconsiderar a versão standard de De Crescenzo.

Quadro 1 - Sentenças e frases em napolitano, italiano e tradução para o português

\begin{tabular}{|c|c|c|}
\hline Napolitano & $\begin{array}{l}\text { Tradução para italiano/ } \\
\text { notas de De Crescenzo }\end{array}$ & $\begin{array}{l}\text { Tradução em } \\
\text { português }\end{array}$ \\
\hline $\begin{array}{l}\text { Professò, po' ce sta 'o cuoco, } \\
\text { 'a tavulella cu' e' ddoie } \\
\text { coppie assettate, 'o } \\
\text { mellunaro, o' verdummaro, } \\
\text { chille ca venne 'e castagne, 'o } \\
\text { canteniere, 'o chianchiere (DE } \\
\text { CRESCENZO, 2010b, p. 43). }\end{array}$ & $\begin{array}{l}\text { Il cuoco, la tavola con le } \\
\text { due coppie sedute, il } \\
\text { venditore di cocomeri, il } \\
\text { verdumaio, quello che } \\
\text { vende le castagne, il } \\
\text { vinaio, il macellaio. }\end{array}$ & $\begin{array}{c}\text { Professor, estavam o } \\
\text { cozinheiro, a mesa com } \\
\text { os dois casais sentados, } \\
\text { o vendedor de melancias, } \\
\text { o verdureiro, aquele que } \\
\text { vende as castanhas, o } \\
\text { vendedor de vinhos e } \\
\text { o açougueiro. }\end{array}$ \\
\hline $\begin{array}{l}\text { Mamma bella d'o Carmine } \\
\text { (DE CRESCENZO, 2010b, } \\
\text { p. 58). }\end{array}$ & $\begin{array}{c}\text { Madonna bella del } \\
\text { Carmine - esclamasione di } \\
\text { paura. }\end{array}$ & $\begin{array}{l}\text { Nossa Senhora do } \\
\text { Carmo - exclamação } \\
\text { de medo. }\end{array}$ \\
\hline $\begin{array}{l}\text { Tu guarda a chist' } \\
\text { disgraziato comme s'è } \\
\text { 'mpezzato! (DE CRESCENZO, } \\
\text { 2010b, p. 98). }\end{array}$ & come si è infilato. & $\begin{array}{c}\text { Olhe para esse } \\
\text { desgraçado como se } \\
\text { enfia }^{14}\end{array}$ \\
\hline $\begin{array}{l}\text { Io mò voglio proprio vedè chi } \\
\text { è stu piezze 'e fetente. Gesù, } \\
\text { Gesù, ma chella è 'na } \\
\text { femmena! Tu vide che se } \\
\text { passa. Pure 'e femmene ce } \\
\text { vulevano! Invece 'e fa 'e } \\
\text { zoccole 'mmiez a via, } \\
\text { statavenne 'a casa vosta! (DE } \\
\text { CRESCENZO, 2010b, p. 99). }\end{array}$ & $\begin{array}{c}\text { Io adesso voglio proprio } \\
\text { vedere che è questo pezzo } \\
\text { di fetente. Gesù Gesù ma } \\
\text { quella è una donna! Anche } \\
\text { le donne ci volevano! } \\
\text { Invece difare le puttane } \\
\text { per la strada, restate nelle } \\
\text { vostre case! }\end{array}$ & $\begin{array}{l}\text { Agora eu quero ver } \\
\text { quem é esse desgraçado. } \\
\text { Jesus, Jesus, mas é } \\
\text { uma mulher! Até as } \\
\text { mulheres estão aqui! Em } \\
\text { lugar de ficarem se } \\
\text { fazendo de putas pelas } \\
\text { ruas, fiquem em suas } \\
\text { casas! }\end{array}$ \\
\hline $\begin{array}{l}\text { Con le pacche nell'acqua (DE } \\
\text { CRESCENZO, 2010b, p. 137). }\end{array}$ & in pessime condizioni. & Em péssimas condições. \\
\hline
\end{tabular}


Quadro 1 - Sentenças e frases em napolitano, italiano e tradução para o português (conclusão)

\begin{tabular}{|c|c|c|}
\hline Napolitano & $\begin{array}{l}\text { Tradução para italiano/ } \\
\text { notas de De Crescenzo }\end{array}$ & $\begin{array}{l}\text { Tradução em } \\
\text { português }\end{array}$ \\
\hline $\begin{array}{l}\text { A Napoli si dice: è meglio } \\
\text { cumonnà che fottere (DE } \\
\text { CRESCENZO, 2010b, p. 139). }\end{array}$ & - & $\begin{array}{l}\text { Em Nápoles se diz: é } \\
\text { melhor mandar do que } \\
\text { foder. }\end{array}$ \\
\hline $\begin{array}{l}\text { Puveriello è pate e figli e nun } \\
\text { sape sunà! (DE CRESCENZO, } \\
2010 \text { b, p. 148). }\end{array}$ & $\begin{array}{l}\text { Poveretto, è padre di figli e } \\
\text { non sa suonare. }\end{array}$ & $\begin{array}{c}\text { Pobrezinho, é pai de } \\
\text { filhos e não sabe tocar }{ }^{15} \text {. }\end{array}$ \\
\hline $\begin{array}{l}\text { Và trova Annucia mò addò } \\
\text { sta (DE CRESCENZO, } \\
\text { 2010b, p. 170). }\end{array}$ & $\begin{array}{l}\text { Chissà Annuncia adesso } \\
\text { dov'è. }\end{array}$ & $\begin{array}{c}\text { Onde será que } \\
\text { Annuncia se encontra? }\end{array}$ \\
\hline $\begin{array}{l}\text { Chist'è nu fuosso. Antonio } \\
\text { sta vicino o' fuosso e sta } \\
\text { aspettann'a Pascale pecchè } \\
\text { tenano n'appuntamento. } \\
\text { Dice Antonio vicino a } \\
\text { Pascale: "Pascà, te sto } \\
\text { aspetanno a' tantu tiempo" } \\
\text { poi rivolto a noi “Stateve } \\
\text { ‘bbuone ve ne putite 'i”. (DE } \\
\text { CRESCENZO, 2010b, } \\
\text { p. 193). }\end{array}$ & $\begin{array}{c}\text { Statevi bene, ve ne potete } \\
\text { andare. }\end{array}$ & $\begin{array}{l}\text { Estão perto do fosso. } \\
\text { Antonio está perto do } \\
\text { fosso e está esperando } \\
\text { Pascale porque têm um } \\
\text { compromisso. Disse } \\
\text { Antonio perto de Pascale: } \\
\text { "Pascale, estou te } \\
\text { esperando há tanto } \\
\text { tempo" depois se voltou a } \\
\text { nós "Fiquem tranquilos, } \\
\text { vocês podem ir". }\end{array}$ \\
\hline $\begin{array}{l}\text { O vedite? A me m'hanno } \\
\text { avvelenate e mò me vonno } \\
\text { pure 'accidere. E ci 'hanno } \\
\text { raggione lloro quanno diceno } \\
\text { ca nu pisciavinnolo nun pò } \\
\text { addeventa generalissimo d'a } \\
\text { pupulazzione a nu mumento } \\
\text { a n'ato. Ma io nun vulevo fa } \\
\text { niente 'e male e manco niente } \\
\text { uoglio. Chi me vo bbene } \\
\text { overamente dicesse sulo na } \\
\text { preghiera pe me: nu requia- } \\
\text { eterna e basta pè quanno } \\
\text { moro. P'o riesto vo ttorno 'a } \\
\text { dì: nun voglio niente. Annudo } \\
\text { so nato e annudo voglio muri } \\
\text { (DE CRESCENZO, 2010b, } \\
\text { p. 206). }\end{array}$ & $\begin{array}{c}\text { Lo vedete? A me hanno } \\
\text { dato il veleno e adesso mi } \\
\text { vogliono anche uccidere. Ed } \\
\text { hanno ragione loro quando } \\
\text { dicono che un pescivendolo } \\
\text { non può diventare } \\
\text { generalissimo del popolo } \\
\text { da un momento all'altro. } \\
\text { Ma io non volevo far niente } \\
\text { di male e nemmeno niente } \\
\text { voglio. Chi mi vuol bene } \\
\text { veramente dica per me solo } \\
\text { una preghiera: un requiem } \\
\text { soltanto per quando muoio. } \\
\text { Per il resto, ve lo torno a } \\
\text { dire: non voglio niente. } \\
\text { Nudo sono nato e nudo } \\
\text { voglio morire. }\end{array}$ & $\begin{array}{l}\text { Vocês veem? Deram o } \\
\text { veneno a mim e agora } \\
\text { querem também me } \\
\text { matar. E eles têm razão } \\
\text { quando dizem que um } \\
\text { peixeiro não pode se } \\
\text { tornar general do povo } \\
\text { de uma hora para outra. } \\
\text { Mas eu não quero fazer } \\
\text { nada de mal e nem } \\
\text { quero nada. Quem me } \\
\text { quer verdadeiramente } \\
\text { bem faça uma oração } \\
\text { para mim: um réquiem } \\
\text { unicamente para } \\
\text { quando eu morrer. Pelo } \\
\text { resto, eu vos torno a } \\
\text { dizer: não quero nada. } \\
\text { Nasci nu e nu quero } \\
\text { morrer. }\end{array}$ \\
\hline
\end{tabular}

15 Piada sexual, como se o personagem dissesse: "Coitado, tem um filho mas não sabe fazer sexo". 
É possivel observar, entre outras características linguísticas, a diferença lexical do italiano e do dialeto, como em canteniere versus vinaio (vendedor de vinho), chianchiere versus macellaio (açougueiro), femmene versus donna (mulher). Além disso, utilizando as frases e expressões dialetais, como Con le pacche nell'acqua ou A Napoli si dice: è meglio cumonnà che fottere, o autor marca o vínculo entre personagem e espaço, pois evidencia, literariamente, os costumes linguísticos desse povo. O uso dos verbos, adjetivos e principalmente dos substantivos, como pezza (dinheiro) ou 'a guenga (a banda), dispõe ao leitor como os napolitanos nomeiam os objetos e as coisas ao seu redor, aproximando-o, então, a como os personagens vivenciam Nápoles. Assim, o léxico napolitano é usado em abundância, como também se pode verificar nos exemplos apresentados no Quadro 2, que evidenciam palavras em napolitano utilizadas no romance, seguidas da tradução italiana proposta pelo autor e a nossa versão em português.

Quadro 2 - Palavras em napolitano usadas nos diálogos

\begin{tabular}{|c|c|c|}
\hline Napolitano & $\begin{array}{c}\text { Tradução para } \\
\text { italiano/ notas } \\
\text { de De Crescenzo }\end{array}$ & $\begin{array}{c}\text { Tradução em } \\
\text { português }\end{array}$ \\
\hline Pezza (DE CRESCENZO, 2010b, p. 32) & Denaro & Dinheiro \\
\hline Abbuscare (DE CRESCENZO, 2010b, p. 35) & Guadagnare & Ganhar \\
\hline Fuiarella (DE CRESCENZO, 2010b, p. 46) & Fuga precipitosa & $\begin{array}{c}\text { Fuga } \\
\text { apressada }\end{array}$ \\
\hline Appicciate (DE CRESCENZO, 2010b, p. 51) & Litigate & Brigar \\
\hline $\begin{array}{l}\text { Addobbochiamento (DE CRESCENZO, 2010b, } \\
\text { p. 55) }\end{array}$ & Sonnolenza & Sonolência \\
\hline 'a guenga (DE CRESCENZO, 2010b, p. 167) & La banda & A banda \\
\hline Scoppole (DE CRESCENZO, 2010b, p. 167) & Scappellotti & Tapas \\
\hline Cuppulone (DE CRESCENZO, 2010b, p. 167) & Grande cappelo & $\begin{array}{l}\text { Chapéu } \\
\text { grande }\end{array}$ \\
\hline Quequera (DE CRESCENZO, 2010b, p. 167) & Ridicola & Ridícula \\
\hline Sparpetuo (DE CRESCENZO, 2010b, p. 168) & Attesa tediosa & Espera tediosa \\
\hline
\end{tabular}

O uso de palavras ou frases napolitanas é mais intenso nos diálogos dos personagens Saverio e Salvatore, fato que acreditamos ser pensado pelo escritor para evidenciar as características mais latentes desses personagens configurados no romance.

O personagem Saverio é o segundo que mais usa o dialeto, seguido de Luigino e do professor Bellavista, mas Salvatore é o personagem que mais tem o napolitano registrado em suas falas, como nos trechos do Quadro 3. 
Quadro 3 - Dialeto napolitano presente nos discursos diretos de Salvatore

\begin{tabular}{|c|c|c|}
\hline Napolitano & $\begin{array}{c}\text { Tradução para } \\
\text { italiano/ notas } \\
\text { de De Crescenzo }\end{array}$ & $\begin{array}{l}\text { Tradução em } \\
\text { português }\end{array}$ \\
\hline $\begin{array}{l}\text { "Insomma, dottò, in parole povere, ci } \\
\text { puzzeremmo" (DE CRESCENZO, 2010b, } \\
\text { p. 14, grifo do autor). }\end{array}$ & $\begin{array}{c}\text { Sta per } \\
\text { moriremmo. }\end{array}$ & $\begin{array}{c}\text { Resumindo, doutor, } \\
\text { em poucas palavras, } \\
\text { nós federemos depois } \\
\text { de morrer. }\end{array}$ \\
\hline $\begin{array}{l}\text { “[...] dove giorno e notte mi zucavo il } \\
\text { fumo dell”Ilva” (DE CRESCENZO, } \\
2010 b \text {, p. 15, grifo do autor). }\end{array}$ & Sorbivo & $\begin{array}{l}\text { onde dia e noite eu } \\
\text { fumava lentamente o } \\
\text { fumo da Ilva. }\end{array}$ \\
\hline $\begin{array}{l}\text { “[...] e come sentite comunista subito vi } \\
\text { appicciate” (DE CRESCENZO, 2010b, } \\
\text { p. 17, grifo do autor). }\end{array}$ & Accendete & $\begin{array}{l}\text { e quando vocês } \\
\text { ouvem "comunistas", } \\
\text { logo iniciam uma } \\
\text { briga. }\end{array}$ \\
\hline $\begin{array}{l}\text { "Il guaio, dottò, è che voi misurate tutto } \\
\text { ad automobili e panzarotti” (DE } \\
\text { CRESCENZO, 2010b, p. 20, grifo do } \\
\text { autor). }\end{array}$ & $\begin{array}{l}\text { Crocchette di } \\
\text { patate }\end{array}$ & $\begin{array}{l}\text { O problema, doutor, } \\
\text { é que vocês avaliam } \\
\text { tudo por carros e } \\
\text { croquetes recheados. }\end{array}$ \\
\hline $\begin{array}{l}\text { "[...] senza voler fare mancamento" } \\
\text { (DE CRESCENZO, 2010b, p. } 28 \text {, grifo } \\
\text { do autor). }\end{array}$ & $\begin{array}{l}\text { Senza volervi } \\
\text { sminuire }\end{array}$ & $\begin{array}{l}\text { sem querer te } \\
\text { diminuir. }\end{array}$ \\
\hline $\begin{array}{l}\text { "[...] lui parla e noi beviamo, e ci } \\
\text { facciamo pure il percuoco a fette nel } \\
\text { vino" (DE CRESCENZO, 2010b, p. } 29 \text {, } \\
\text { grifo do autor). }\end{array}$ & La pesca gialla & $\begin{array}{l}\text { ele fala e nós } \\
\text { bebemos, e fazemos } \\
\text { também pêssegos } \\
\text { fatiados no vinho. }\end{array}$ \\
\hline $\begin{array}{l}\text { "Martedi mi fece una cancheriata (DE } \\
\text { CRESCENZO, 2010b, p. 39, grifo do } \\
\text { autor). }\end{array}$ & Sgridata & $\begin{array}{l}\text { Na terça-feira, } \\
\text { chamou-me a } \\
\text { atenção. }\end{array}$ \\
\hline $\begin{array}{l}\text { “O' presepe! L'addore d'a colla 'e pesce, } \\
\text { 'o suvero pe fa 'e muntagne, 'a farina pe } \\
\text { fa 'a neve" (DE CRESCENZO, 2010b, } \\
\text { p. } 43 \text {, grifo do autor). }\end{array}$ & $\begin{array}{l}\text { L'odore } \\
\text { Il sughero }\end{array}$ & $\begin{array}{l}\text { O presépio, o odor da } \\
\text { cola de peixe }{ }^{16}, \text { a } \\
\text { cortiça para fazer as } \\
\text { montanhas e a } \\
\text { farinha para fazer a } \\
\text { neve. }\end{array}$ \\
\hline $\begin{array}{l}\text { “[...] scherzando scherzando si prendono } \\
\text { a paccheri” (DE CRESCENZO, 2010b, } \\
\text { p. } 51 \text {, grifo do autor). }\end{array}$ & Schiaffi & $\begin{array}{l}\text { brincando, brincando } \\
\text { vão acabar saindo no } \\
\text { tapa. }\end{array}$ \\
\hline $\begin{array}{l}\text { “[...] ti avrebbe dato tanti di quei } \\
\text { boffettoni” (DE CRESCENZO, 2010b, } \\
\text { p. 175, grifo do autor) }\end{array}$ & $\begin{array}{l}\text { Ceffoni molto } \\
\text { rumorosi }\end{array}$ & $\begin{array}{c}\text { te daria tantas } \\
\text { daquelas bofetadas. }\end{array}$ \\
\hline
\end{tabular}

16 Gelatina incolor e inodora à base de peixe. 
De fato, o napolitano é encontrado amplamente nos capítulos nos quais os personagens Saverio e Salvatore mais têm falas, já nos capítulos nos quais o professor Bellavista explica suas teorias filosóficas, o dialeto não é usado em quase nenhum momento. Acreditamos que o fato de Saverio e Salvatore serem os personagens socioeconomicamente menos privilegiados e terem uma convivência praticamente entre amigos e família resulte no uso mais recorrente do dialeto napolitano, pois atuam quase que exclusivamente no nivel informal, evidenciando as diferenças socioeducativas entre esses personagens e os outros que são formados e têm empregos valorizados, como o do professor Bellavista e o do engenheiro De Crescenzo, que atuam tanto em nivel formal, utilizando a lingua oficial com frequência, quanto em nivel informal, e que, por isso, teriam mais convivência com o italiano standard, valendo-se mais dessa lingua.

O uso da língua oficial e dos dialetos regionais, no caso da Itália, estabelece a relação de identidade entre seus habitantes e a regionalidade de cada um deles. Assim, fica evidenciado que o uso do dialeto na obra decrescenziana mescla a cultura do povo napolitano e a presença linguística de Nápoles não somente na obra-prima, mas também nas reescrituras mitológicas decrescenzianas. Segundo Isabela Barros e Daniele Lima (2017, p. 25):

[...] a identidade cultural vai se firmando com suas características próprias $e$ definindo o povo. A identidade cultural expõe o sujeito que se encontra marcado na língua ao fazer referência a si e ao seu povo quando utiliza uma forma dialetal no seu discurso. Ou seja, é através das marcas enunciativas que é possível reconhecer a identidade do sujeito falante.

Percebe-se, portanto, que o dialeto caracteriza os personagens, cria vínculo entre eles e a cultura napolitana e destaca as expressões próprias da língua, indicando o contexto no qual se passam as cenas narradas em Così parlò Bellavista e que configuram a cidade natal do escritor que construiu Elena, Elena amore mio, Nessuno e Ulisse era un fico.

A identidade napolitana não é somente configurada pelo espaço, por meio da inserção declarada de ruas conhecidas, castelos famosos, praças e monumentos da cidade de Nápoles, está também demarcada como identidade linguística dos personagens e do próprio escritor que, no caso de Così parlò Bellavista, traduziu para o italiano standard uma narrativa que lhe nasceu mentalmente em dialeto, foi gravada em formato áudio nessa linguagem para depois ser transcrita para o idioma mais formal por ele próprio, mantendo frases, expressões e palavras, de forma a deixar bem determinada não somente a identidade de diversos personagens que ali se manifestam, mas também a própria identidade do escritor Luciano De Crescenzo, demarcando assim o espaço geográfico, cultural e linguístico que os identifica.

\section{NEAPOLITAN IDENTITY, LANGUAGE AND CULTURE IN THE WORKS OF LUCIANO De Crescenzo}

Abstract: We analyze how the Italian writer Luciano De Crescenzo inserts the Neapolitan dialect in his works, such as in Così parlò Bellavista (1977), Elena, Elena, amore mio (1991), Nessuno (1997) and Ulisse è un fico (2010a). We focused, considering the identity and the dialect studies, respectively, in the authors 
Raimondi (1998) and Santos e De Blasi (2010) to investigate how dialectal use demarcates Neapolitan identity and culture. Although the works are written in standard Italian, by inserting phrases, popular sayings, idioms and lyrics in dialectal variant into the characters' discourse and into the narrator's comments, the author, creatively, explores the linguistic reality of that Italian region.

Keywords: Luciano De Crescenzo. Neapolitan dialect. Identity.

\section{REFERÊNCIAS}

BARROS, I.; LIMA, D. O homem na língua: o dialeto como índice de subjetividade e identidade cultural. Revista Desenredo, v. 13 n. 1, 2017. DOI 10.5335/ rdes.v13i1.6799.

BRACALE, R. La nascita del dialetto/idioma napoletano. 2010. Disponivel em: http://www.ilportaledelsud.org/napoletano.htm. Acesso em: 26 abr. 2019.

CAUTI, C. O renascimento dos dialetos na Itália. Exame, 8 abr. 2017. Disponivel em: https:// exame.abril.com.br/mundo/o-renascimento-dos-dialetos-na-italia. Acesso em: 26 abr. 2019.

COSTAMAGNA, L. Cantare l'italiano. Perugia: Guerra, 1995.

DE CRESCENZO, L. Così parlò Bellavista. Milano: Mondadori, 1977.

DE CRESCENZO, L. Elena, Elena, amore mio. Milano: Mondadori, 1991.

DE CRESCENZO, L. Nessuno. Milano: Mondadori, 1997.

DE CRESCENZO, L. Ulisse era un fico. Milano: Mondadori, 2010a.

DE CRESCENZO, L. Così parlò Bellavista: Napoli, amore e libertà. 37. rist. Milano: Mondadori, 2010b.

KELLY, S. The cronaca di Partenope: an introduction to and critical edition of the first vernacular history of Naples. Leiden: Brill, 2011.

MARANO, L. Aspetti sintattici dell'italiano parlato a Napoli: un'analisi diagenereazionale. 2010. Tese (Dottorato) - Università degli Studi di Napoli Federico II, Napoli, 2010. Disponivel em: http://www.fedoa.unina.it/8035. Acesso em: 26 abr. 2019.

RAIMONDI, E. Letteratura e identità nazionale. Milano: Mondadori, 1998.

SANTOS, A. C. R.; DE BLASI, N. Falantes em nome da lei: indícios de uma questão linguística em Nápoles no início do século XXI. Linguasagem, São Paulo, v. 1, p. 1-7, 2010.

ZAPPETTINI, F. Lingua e identità sociale. 2016. Disponivel em: https://www. academia.edu/3491529/Lingua_e_identita_sociale_2015. Acesso em: 26 abr. 2019. 